\title{
Playing and Cheating in Ambient Entertainment
}

\author{
Anton Nijholt \\ University of Twente, Human Media Interaction \\ PO Box 217, 7500 AE Enschede, The Netherlands \\ anijholt@cs.utwente.nl
}

\begin{abstract}
We survey ways to extract information from users interacting in ambient intelligence entertainment environments. We speculate on the use of this information, including information obtained from physiological processes and brain-computer interfacing, in future game environments.
\end{abstract}

Keywords: Entertainment computing, nonverbal interaction, cheating.

\section{Introduction}

In future Ambient Intelligence (AmI) environments we assume intelligence embedded in the environment, its objects (furniture, mobile robots) and its virtual, sometimes visualized agents (virtual humans). These environments support the human inhabitants or visitors of these environments in their activities and interactions by perceiving them through their sensors (proximity sensors, cameras, microphones, etc.). Support can be reactive, but also and more importantly, pro-active and unobtrusive, anticipating the needs of the inhabitants and visitors by sensing their behavioral signals and being aware of the context in which they act [1].

Health, recreation, sports and playing games are among the needs inhabitants and visitors of smart environments will have. Sensors in these environments can detect and interpret nonverbal activity and can give multimedia feedback to invite, stimulate, guide, advise and engage. Activity can aim at improving physical and mental health (well-being), but also at improving capabilities related to a profession (ballet, etc.), recreation (juggling, etc.), or sports (fencing, etc.). Fun, just fun, to be achieved from interaction can be another aim of such environments.

For many of these (envisioned) applications, the nonverbal interactions with the environment are important and need to be recognized and interpreted. And, rather than having a rather regulated process of turn taking as in dialogue systems, in these applications the main flow of events is continuous, rather than segmented.

In this paper we look at nonverbal interaction in ambient entertainment applications. How is the environment going to use such information? For example, in an entertainment game, will the environment use this information to make the experience more attractive for the user, providing him or her with more chances, or should the environment be in competition with the user and employ all information that can be derived from the user's behavior to win? In the latter case, the human gamer may try to hide his or her intentions in order to mislead the environment. 
Information that can be taken into account is physiological information, including information obtained from measuring brain activity (brain-computer interfacing). Again, this knowledge can be used to adapt the interaction with the user in a particular entertainment game situation. And, in a situation where we really compete with the computer we need to be aware that the computer is using this information against us. Can we control our nonverbal behavior, our physiological processes and our brain activity in such a way that we can mislead the computer?

\section{Dance, Music, Sports, and Fitness}

Entertainment, health, sports, and leisure applications using information and communication technology often require and encourage physical body movements and often applications are designed for that reason. In our research we look at bodily and gestural interaction with game and leisure environments that are equipped with sensors (cameras, microphones, touch, and proximity sensors) and applicationdependent intelligence (allowing reactive and proactive activity). Interpretation of the bodily interaction, requiring domain-dependent artificial intelligence, needs to be done by the environment and the agents that maintain the interaction with the human partner. In the display of reactive and pro-active activity embodied virtual agents play an important role. Virtual agents can play the role of teacher, coach, partner or game opponent. Hence, there are, among others, a virtual therapist that helps patients to recover from injuries [2], a Tai Chi training master [3], and a shadow boxer [4].

We have designed applications in which our ideas about nonverbal and bodily interaction have been implemented [5,6,7]. We looked at the design, implementation and evaluation of a virtual dancer that invites a visitor to dance with her, a conductor that guides musicians in their playing, and a virtual trainer that helps a user or patient in his exercises. In the applications there is a continuous interaction between an embodied agent and a human partner. Rather than have the more traditional verbal interaction supported by nonverbal communication, here the main interaction is nonverbal. Speech and language, when present at all, have a supporting role. In these applications there is multimodal analysis of a user's activities.

\section{Learning to Know the User}

In AmI environments user profiles are maintained. The profile will continuously be adapted by new information made available by the user (not necessarily with the aim to have its profile updated). Our environments perceive a user's activities and use that information to learn about the user (and adapt and extend his profile).

In order to learn about the user, his or her personality, his or her 'human values' and attitudes, questionnaires have been designed. In [8] it is remarked that "Personality represents those characteristics of the person that account for consistent patterns of feeling, thinking, and behaving." Without doubt, in face-to-face interaction, our interaction behavior does not only depend on our own personality, but also on the personality characteristics that we try to derive from the behavior of our 
partner in the interaction and that we attribute to our interaction partner or to the profile we made up from already available information about our interaction partner.

Questionnaires that aim to measure personality are well-known. They depend on models of personality theory (trait theory, personal construct theory, psychodynamic theory, etc.). In educational environments it is not unusual to take into account personality characteristics and associated questionnaires in order to be able to match learning styles with tutoring strategies, and the display of feedback. Using a user's scores on personality dimensions in order to adapt a game is an unexplored area of game and entertainment research. When we know that a particular user has a high score on curiosity, creativity and untraditional (high scores on Openness), we can make use of that. Similarly, it also helps if we know that a user is cynical, rude and uncooperative (low scores on Agreeableness).

Many other questionnaires exist. Apart from personality we can look at questionnaires that measure intelligence and emotional intelligence. Moreover there are questionnaires that aim to measure the values a user has. A good example is the so-called Human Values Scale [9] and in particular how it is used in the context of recommender systems [10]. There are also questionnaires that aim at extracting information that is more directly related to educational, game, and entertainment situations [11]. Hence, we can look at decision-making style questionnaires where thoroughness, control, hesitancy, social resistance, perfectionism, idealism and instinctiveness are among the issues that are assessed, and we can look at questionnaires where we can look at a players willingness to empathize with other personality characters in a game (see e.g. the empathy questionnaire [12].

Summarizing, to answer the question what the environment can learn about the user, we can look at demographic information that has been collected, information about the user that can be generated from 'external' sources (email content and communication, web page visits, Skype, device use, etc.), information about the context (what behavior can be expected), and information that can be obtained from filled-in forms and questionnaires that tell us about intelligence, personality, emotional intelligence, and more specialized questionnaires that help us to anticipate gaming styles, and decision making behavior. Obviously, it is far from natural to ask people to fill in questionnaires.

\section{Learning from Behavior in the Entertainment Environment}

Although information about the entertainment gamer can be obtained through questionnaires, as mentioned in the previous section, this is a rather unnatural way and we can not expect that people are willing to spend time before starting to play.

There are also possibilities to obtain information about the user by hiding the questionnaires in a playful interaction with the user. For example, in [13] an attempt is made to score personality by means of an informal conversation where elements of the traditional questionnaires are merged into the conversation by the computer. Interesting is also the approach in [14], where music preferences are correlated with personality dimensions. This approach fits in a framework correlating personality dimensions and behavior that occurs in everyday life. 
In AmI environments we have the technology to capture human behavior in everyday life. In our ambient entertainment view the same technology is available and we can either assume that behavior of a particular user or visitor of our ambient entertainment environment already carries a user profile that has been generated from the user's behavior in the past, or we can assume that during a possibly playful interaction with the environment a profile can be obtained and can be used by the environment to adapt to the user's characteristics.

What can we learn from behavioral information captured by cameras, microphones and other types of sensors? In [15] results are reported from short observations of expressive behavior. Observations include the assessment of relationships, distinguishing anxious and depressed people from normal people, predicting judges' expectations for a trial outcome, determining political views of television newscasters, etc. Personality judgments from 'thin slices of behavior' and their accuracy are also discussed in [16]. An example where real-time behavioral analysis is done by a computer can be found in [17]. Here a participant is invited in front of a video camera for about 30 seconds. After that a personality profile is generated.

\section{Playing with Behavioral Information}

\subsection{Taking into Account Involuntary User Responses}

In the examples mentioned earlier we have bodily interaction with the computer system. Input to an entertainment environment can be based on conscious decisions made by the human. This is usually the case when keyboard, mouse or joystick is used. Behavioral signals and patterns during activities provide (additional) information about the tasks that a user wants to perform, the way they should be performed and the user's appreciation of task, performance, and context. Sensing and understanding these signals is an important issue in 'human computing' [1] and it makes human computing an important area of research for entertainment computing. This kind of input is not always consciously provided by a user and is sometimes beyond the control of the user. Behavioral signals also provide information about the affective state of the user and this information is useful to adapt the environment (more or less control by the user, other challenges, etc.) to the user.

More information about the affective state of the user of an entertainment environment can be obtained by collecting and interpreting information obtained from measuring physiological processes and brain activity. Physiological cues are obtained from, for example, respiration, heart rate, pulse, skin temperature and conductance, perspiration, muscle action potentials and blood pressure [18,19]. Unfortunately, this information can mostly not be obtained unobtrusively. Finally, we should mention measured brain activity. Again, measuring brain activity, e.g. by using an EEG cap, can provide information about the affective state of the user (frustration, engagement, etc.) and this can be used to dynamically adapt the interface to the user and provide tailored feedback. 


\subsection{User Control of 'Involuntary' Responses}

Playing against a computer is not fair. The computer knows about our affective state and can decide to use it or to communicate it to our (virtual) opponents or team players in the environment who can use it to their advantage. On the other hand, apart from adapting the environment, the computer can also make the human player aware of his affective state so that he can make an attempt to control it since it can decrease own performance and give away unwanted information to other players in the game.

In games and sports opponents can be misled. We can as well try to mislead or tease our virtual and human partners who play in a computer-controlled environment. One step further is that we have entertainment games where misleading the computer is an essential part of the game. A simple example is playing soccer against a humanoid robot and the robot's aim is to win rather than to offer its human partner an enjoyable experience. In such a situation misleading means for example making feints. But also, trying to look more tired than we really are and all other kinds of misleading behavior that we can think of. In our virtual dancer installation human dancers sometimes try to tease the virtual dancer by acting unexpected and then look how she reacts. In other environments we may want to hide our intentions from the computer by controlling our facial expressions (e.g., in a poker game with a computer that can observe us). Once we know that our non-human opponent is receptive for our behavioral, physiological or brain processes, we need to cheat in order to obtain more satisfaction from the entertainment game. Game research in this direction is rare, but it is well-known that people can learn to control, up to a certain level, these processes. Research and development in among others brain-computer interfacing makes clear that interesting new types of entertainment in which ideas described above can be incorporated will become available in the future $[20,21]$.

\section{Conclusions}

We looked at ways to provide the computer in an entertainment environment with as much information about ourselves and our preferences as possible. In particular we looked at ways for a computer to extract this information automatically from our behavior. We also looked at the computer as our opponent rather than as provider of enjoyable experiences. We then prefer to mislead the computer and hide information about our affective state or even control and manipulate our behavioral, physiological and brain processes so that we consciously provide the computer with misinformation allowing us to become the 'winner' in smart entertainment environments.

\section{References}

1. Pantic, M., Pentland, A., Nijholt, A., Huang, T.: Human Computing and Machine Understanding of Human Behavior: A Survey. In: Pantic, M., et al. (ed.) AI for Human Computing. LNCS (LNAI), vol. 4451, pp. 47-71. Springer, Heidelberg (2007)

2. Babu, S., Zanbaka, C., Jackson, J., Chung, T-O., Lok, B., Shin, M.C., Hodges, L.F.: Virtual Human Physiotherapist Framework for Personalized Training and Rehabilitation. In: Graphics Interface 2005, Victoria, British Columbia, Canada (2005) 
3. Chua, P.T., Crivella, R., Daly, B., Hu, N., Schaaf, R., Ventura, D., Camill, T., Hodgins, J., Pausch, R.: Training for Physical Tasks in Virtual Environments: Tai Chi. In: IEEE Virtual Reality 2003, pp. 87-94. IEEE Computer Society Press, Washington, DC (2003)

4. Höysniemi, J., Aula, A., Auvinen, P., Hännikäinen, J., Hämäläinen, P.: Shadow boxer: a physically interactive fitness game. In: Third Nordic Conference on Human-Computer interaction (NordiCHI '04), vol. 82, pp. 389-392. ACM Press, New York (2004)

5. Reidsma, D., van Welbergen, H., Poppe, R., Bos, P., Nijholt, A.: Towards Bi-directional Dancing Interaction. In: Harper, R., Rauterberg, M., Combetto, M. (eds.) ICEC 2006. LNCS, vol. 4161, pp. 1-12. Springer, Heidelberg (2006)

6. Bos, P., Reidsma, D., Ruttkay, Z., Nijholt, A.: Interacting with a Virtual Conductor. In: Harper, R., Rauterberg, M., Combetto, M. (eds.) ICEC 2006. LNCS, vol. 4161, pp. 25-30. Springer, Heidelberg (2006)

7. Ruttkay, Z., Zwiers, J., van Welbergen, H., Reidsma, D.: Towards a Reactive Virtual Trainer. In: Gratch, J., Young, M., Aylett, R., Ballin, D., Olivier, P. (eds.) IVA 2006. LNCS (LNAI), vol. 4133, pp. 292-303. Springer, Heidelberg (2006)

8. Pervin, L.A., John, O.P.: Personality: theory and research. John Wiley and Sons, Chichester (2001)

9. Schwartz, S.H.: A Proposal for Measuring Value Orientations across Nations; The Hebrew University of Jerusalem (2003)

10. Guzmán, J., González, G., De La Rosa, J.L., Castán, J.: Human Values Scale: Modeling the Human Values Scale in Recommender Systems: A first approach. In: López, B., Meléndez, J., Radeva, P., Vitriá, J. (eds.) Artificial Intelligence Research and Development, vol. 131, pp. 405-412. IOS Press, Amsterdam (2005)

11. Douse, N.A., McManus, I.C.: The Personality of Fantasy Game Players. British Journal of Psychology 84(4), 505-509 (1993)

12. Davis, M.H.: Measuring individual differences in empathy: Evidence for a multidimensional approach. J. of Personality and Social Psychology 44, 113-126 (1983)

13. Bodewitz, M.J.: Measuring personality by means of a computer dialog. MSc. thesis, HMI, University of Twente (2004)

14. Rentfrow, P.J., Gosling, S.D.: The Do Re Mi's of Everyday Life. J. of Personality and Social Psychology 84(6), 1236-1256 (2003)

15. Ambady, N., Rosenthal, R.: Thin slices of expressive behavior as predictors of interpersonal consequences: A meta-analysis. Psychological Bulletin 111(2), 256-274 (1992)

16. Borkenau, P., Mauer, N., Riemann, R., Spinath, F.M., Angleitner, A.: Thin slices of behavior as cues of personality and intelligence. J. of Personality and Social Psychology 86, 599-614 (2004)

17. Bechinie, M., Grammer, K.: Charisma Cam: A prototype of an intelligent digital sensory organ for virtual humans. In: Rist, T., Aylett, R., Ballin, D., Rickel, J. (eds.) IVA 2003. LNCS (LNAI), vol. 2792, pp. 212-216. Springer, Heidelberg (2003)

18. Picard, R.W., Vyzas, E., Healey, J.: Toward machine emotional intelligence: Analysis of affective physiological state. IEEE Transactions on Pattern Analysis and Machine Intelligence 23(10), 1175-1191 (2001)

19. Picard, R.W., Daily, S.B.: Evaluating affective interactions: Alternatives to asking what users feel. In: Human Factors in Computing Systems. Workshop on Innovative Approaches to Evaluating Affective Interfaces, Portland, OR, (April 2-7, 2005)

20. Gilleade, K., Dix, A., Allanson, J.: Affective Videogames and Modes of Affective Gaming: Assist Me, Challenge Me, Emote Me. In: DIGRA'2005, Vancouver, Canada (2005)

21. Nijholt, A., Tan, D.: Playing with your Brain: Brain-Computer Interfaces and Games. In: Bernhaupt, R., Tscheligi, M. (eds.) Proceedings ACE (International Conference on Advances in Computer Entertainment Technology), pp. 305-306. ACM Press, New York (2007) 